\title{
Higher Education Support for Adjunct Faculty on Institutional Websites
}

\author{
Hans Chun \\ Chaminade University of Honolulu \\ Brian Richardson \\ University of Hawaii at Manoa \\ Darren Iwamoto \\ Chaminade University of Honolulu
}

This exploratory study explores the types and level of explicit support available for adjunct faculty on institution's public-facing websites by analyzing a random sample of 50 non-profit four-year institutions of higher education in the United States. The sample, drawn from the Carnegie Classification, indicates the information strategies for a range of colleges and universities. Public-facing institutional websites are an important source of information that is used by adjunct faculty to acquire information regarding work requirements, academic policies, financial payment information, etc. This study considers the variations in website content and concludes by recommending content and features that support adjunct faculty.

\section{INTRODUCTION}

With structural changes in higher education becoming increasingly associated with greater reliance on adjunct faculty, also referred to as part-time faculty, the traditional organization of institutional support for instructional personnel has faced a changing workforce structure. The majority of faculty members are no longer on a tenure track. Tenured or tenure-track faculty account for only $29 \%$ of the total faculty workforce in the United States (Yakoboski, 2016). At many institutions of higher education, the number of adjunct faculty continues to increase steadily as does the institution's reliance on these instructors due to increasing enrollment or changing workforce strategies. Soon the majority of teaching in higher education will be adjuncts (Komos, 2013). Fruscione (2014) found that in many institutions, adjuncts now make up more than 70 percent of higher education faculty. Many of these adjunct faculty members also face short-term employment at a range of institutions and must actively look for future opportunities.

Many adjunct faculty members report not feeling that they are a part of the academic organization and are not being recognized as a source for knowledge and help (Dolan, 2011). Adjunct faculty often feel "out of the loop" in their connection to the institution, mission and values, and curriculum decisions (Shobe, Murphy-Erby \& Sparks, 2014). The inverse is likely also the case, with many full-time faculty not feeling well-connected to adjunct faculty beyond those they supervise directly. The relationship with the broader institution, or institutions, is likewise tenuous, with few connections existing between adjunct faculty and administration, development opportunities, or life on campus. 
Very little has been documented about how colleges and universities have developed flexible and responsive initiatives for effective professional engagement and development in order to meet the specific needs of adjunct faculty and enhance scholarly approaches to teaching and learning practices (Webb, Wong \& Hubball, 2013). Although many adjuncts ultimately succeed, this is in part due to experiences they have had at other institutions and the limited understanding of success that is tied to adjuncts who are limited to teaching a class. In many cases, a new adjunct faculty member is brought into a teaching situation with little or no readily-available information about what is expected from or available to them as adjunct faculty. However, the learning curve could have been shorter (Berschback, 2010).

Support for adjunct faculty can occur in many ways, such as mentoring, orientation, and professional development programs. One useful source of support is the institution's website, which often contains such resources as employment information, information on learning resources and training, and information on the day-to-day working of the institution. Almahamid, Tweiqat and Almanaseer (2016) discuss the need for a college or university website that is often used as a communications channel for presenting and exchanging information between and among stakeholders. For those who are never or infrequently on-campus, online resources have become increasingly vital. On the other hand, the institution's public-facing website is designed to meet the needs of many different stakeholders, and without a committed adjunct faculty resource area, it is often difficult for adjunct faculty, and especially prospective or new adjunct faculty, to find all of the resources they need or even determine whether resources explicitly for faculty are in fact also for adjunct faculty. The dispersed or private content also reinforces the general status of adjuncts as marginal members of the institution.

The purpose of this study is to determine the extent to which higher education institutions have created coherent, openly accessible web-based resources for adjunct faculty. There are four general scenarios that may exist at a particular institution.

First, there are no resources specifically for adjunct faculty because the institution has not created those resources or, in more extreme situations, have not included adjunct faculty in their public information systems. One could imagine, for instance, adjunct faculty not being included in the online campus directory.

Second, there is a wide range of specific resources that may be available to adjunct faculty, but exist in a fragmented way. Sometimes, these resources may be general, such as parking policies, and the adjunct faculty member is forced to wonder if references to faculty include adjunct faculty, or whether they are grouped with another groups, such as graduate students or staff.

Third, resources may be available on an institution's intranet, accessible only to authorized users. There are likely many instances where resources are available on such closed sites, a situation that merits further research. The question of whether resources should in fact be open or password-protected is a policy question that depends, in part, on whether the information for adjuncts should be accessible only to those with current credentials. However, such closed resources are by definition more difficult to study, difficult to search and access, and inaccessible to those without credentials, which include prospective, newly hired, and former adjunct faculty.

Fourth, the institution may have created focused web resources, including a landing page, devoted to the specific situation encountered by adjunct faculty, much in the same way that an institution might create a page for international students or students pursuing a particular degree. The option creates the ability for adjunct faculty to find the resources, or to even know that they should be looking for those resources.

The current study focuses on the fourth scenario for practical and theoretical reasons. The first and second scenarios are difficult to study directly because they depend in part on the researcher having a clear idea of what resources could be available, so that a search can be made to determine that the resource either does not exist or exists in a fragmented way. The third scenario is practically difficult to undertake in more than a small-scale case study because the resources are password protected, which thus requires access to the institution's intranet. Such a research project would be valuable and would be better guided by an analysis of what institutions have made public. 


\section{LITERATURE REVIEW}

\section{Adjunct Faculty}

The perception that most adjunct faculty teaches at multiple institutions turns out to be the opposite. According to the Faculty Career and Retirement Survey fielded by the TIAA Institute, 79 percent of adjunct faculty work for a single college or university, 17 percent work for two institutions and 4 percent at three or more institutions (Yakoboski, 2016). Administrators can help promote faculty loyalty and intent to stay by monitoring job satisfaction of not only full-time faculty, but adjunct faculty as well (Hoyt, 2012). As institutions of higher education increasingly use adjuncts, it is key to attract and retain qualified faculty against the competition (Dolan, 2011). Colleges and universities benefit from continuing employment of their best adjuncts as they are familiar with the institution and can further develop their teaching skills. Adjunct faculty members can also bring expertise from non-academic sectors into the classroom and be used to teach a single course or multiple courses at a given time. To retain their best adjuncts, administrators should foster a supportive work environment for them (Yakoboski, 2016). However, institutions often fall short in supporting adjunct faculty (Hoyt, 2012). "The overall perception was that an adjunct instructor was a non-entity within the faculty body and was not well known to management" (Dolan, 2011, p.70). Adjunct faculty can further become a highly-developed workforce that institutions can draw upon through support and opportunities for professional development.

The phenomenon of increased reliance on adjunct faculty brings increasing scrutiny concerning the implications for the students and student outcomes (Yakoboski, 2016). As there is an increase with remote adjunct faculty teaching classes online, more institutions of higher education will need to consider how to meet the needs for professional development, socialization and virtual collaboration (Schieffer, 2016). As a growing number of adjunct faculty are online educators, the potential alienation that physical distance can cause has encouraged some academic administrators to look for ways to create a greater sense of community (Dolan, 2011).

Hoyt (2012) describes improving the adjunct faculty work environment that includes training, a website with information for adjuncts, and better communication. Dolan (2011) discussed that many adjuncts favored opportunities to increase knowledge through workshops, seminars, social events and other activities that would help foster a stronger sense of community with peers and administrators.

\section{Professional/Faculty Development}

Adjunct faculty have mixed reviews of the teaching and professional development support provided by their institutions (Yakoboski, 2016). As adjunct faculty are no longer used on an occasional basis in higher education, adjuncts play an increasingly critical role with teaching students in higher education (Langen, 2011). Development of adjunct faculty, however, is not considered a priority at many institutions, but offering an orientation and professional development opportunities should be encouraged to increase their involvement with staff and support services and time on campus (Datray, Saxon \& Martirosyan, 2014). "Our hope is that higher education institutions will consider their responsibility in development of quality adjunct faculty and embrace the adjunct as a positive contributor to the institution" (Morton, 2012, p.396). Most schools and departments provide some form of formal or informal support for adjunct faculty. However, a lack of resources was a main factor for limited adjunct faculty mentorship activities (Shobe, Murphy-Erby \& Sparks, 2014).

With regards to institutional support provided for professional development, adjunct faculty members provide mixed reviews with 56 percent being very satisfied with the support provided for teaching and 23 percent feeling very satisfied with the support provided for professional development and career advancement (Yakoboski, 2016). "Institutions of higher education desire quality adjuncts yet fail to invest in their adjuncts to produce that quality" (Morton, 2012, p.396). Although adjunct faculty were most likely to participate in faculty development events, they also felt the need to participate in "defensive" faculty development, so that their appointments would be renewed (Rutz et al., 2012). Yakoboski (2016) notes newer adjuncts are more dissatisfied than their more established peers with the institutional support provided for professional development and career advancement. 
Datray, Saxon and Martirosyan (2014) recommend providing training for new adjunct faculty, professional development opportunities, assign adjunct faculty to mentors, provide institutional resources and include adjunct faculty in resourcing and strategic initiatives, encourage and support the use of diverse instructional techniques, integrate adjunct faculty in the institutional mainstream, and consider the needs and contributions of adjunct faculty when engaging in course redesign initiatives. Morton (2012) discusses the importance of a facilitator to bring about a mentoring program for adjuncts that can expand teaching and classroom skills. However, some institutions lack the vision, management, or funds to have such a program for adjuncts. The impact of professional development experiences, along with the interactions they generate with other faculty, leads to the establishment of a culture that supports reflective, scholarly teaching (Rutz et al., 2012).

\section{METHODOLOGY}

This exploratory study considers the extent to which higher education institutions have created a sustaining adjunct faculty support page on the university website. A random sample of 50 large and medium non-profit higher-education institutions with Masters degrees was generated based on the Carnegie Foundation's classification of colleges and universities. The pool was composed of institutions that were coded 18 and 19 in the Carnegie Foundation data file (Carnegie, 2015). The sample thus did not include categories such as community colleges or for-profit colleges and universities, which would provide interesting comparisons in future studies.

A computer-generated random sample of the 50 institutions was created. The subsequent analysis utilized content analysis to determine if there is a single page devoted to adjunct faculty. The sample size was chosen to offer an adequate amount of variation while offering a viable amount of content for a content analysis.

Two strategies were adopted for finding the adjunct page. First, the study determined if a page could be accessed with the standardized URL "/adjunct" pathway. In a well-organized website, such a straightforward URL is a test of whether the institution has created a focused resource for that group. "Adjunct" was used as the test URL pathway in part because the term is commonly accepted to refer to teaching faculty in non-permanent teaching roles in higher-education. This test would thus indicate whether an adjunct page existed in the same way that a library page or an admissions page would be expected to exist on the institution's website.

The second strategy to determine the existence of public-facing adjunct resources was to use Google to search the institution's website. The sample was then studied by using site limited searches in GoogleAlabama State University, for instance, would be "adjunct site: alasu.edu" - to determine the general presence of adjunct resources on the site. For each institution, a site-focused Google search was performed to determine what content existed that was explicitly associated with the needs of adjunct faculty. It was assumed that the highest-ranking Google results yielded the most relevant results from that site and if a focused adjunct page existed, it would occur at minimum in the results on the first page of results. Other links to adjunct information, such as found on employment listing pages, were also noted.

\section{RESULTS}

The data generated from the sample indicates that all of the institutions had some information that mentioned adjuncts. At a minimum, there were job postings for adjunct positions, although these postings provided no support to the adjuncts and simply recruitment documents. Twenty-three of the 50 institutions sampled (46\%) had a level of human resources focused on providing information related to employment policies and procedures relevant to adjuncts, which might include details on healthcare and other benefits specific to those with an adjunct faculty status.

Five out of the 50 institutions (10\%) included an adjunct faculty manual uploaded as a PDF. These manuals often were not frequently updated and some were several years old. In addition, the manuals 
tended to focus on institutional policies and regulations, offering little in the way of support or details about the day-to-day activities and resources available to adjunct faculty.

Only three out of 50 institutions sampled (6\%), had a webpage devoted to adjunct faculty beyond human resources employment-related information. These three institutions provided adjuncts with further resources on getting started, such as information or links to information on entering grades, creating a syllabus, aiding students with disability, ordering textbooks, and asking the helpdesk with technical questions. Sometimes this information was tailored to the specific needs of adjunct faculty members, other times the information was more generic if there was no difference between adjunct and full-time faculty. The focus of these pages was on the immediate mechanics of teaching with an emphasis on policies and procedures.

None of the sampled institutions had an adjunct faculty webpage providing links or content connected to ongoing professional development available to adjunct faculty. One university provides a link on an adjunct faculty resource page to their Center for Advancing Faculty Excellence, but that page makes no mention of adjunct faculty. There may be opportunities available, such as trainings open to any faculty and staff, but the adjunct faculty members have no obvious place to search for those opportunities and may not realize or feel that they are welcome to attend.

There was no evidence in the sample of adjunct resources available only on password-protected pages. However, this may be due to that there were few pages devoted to adjunct faculty, so there were few places where such password-protected resources could be accessed (and noted as passwordprotected). The results leave open the possibility that resources appropriate for adjunct faculty are hidden behind password protection, but that their existence is not publicly indicated.

\section{DISCUSSION}

College or university websites have become a primary means for stakeholders to connect with the institution. In contrast, uncertainty and disengagement can occur through a lack of coherent web resources. Higher education institutions tie together disparate groups - students, full-time faculty members, adjunct faculty, staff, administration, etc.-into a complicated system with a common purpose: education. Some groups are in the center of that system, with explicit resources, policies, and a status at the core of the institution's mission and, by implication, of the institution's website. Other groups, even if important to the overall mission, do not share the same status.

This study indicates that higher education institutions have considerable work to do in improving their interactions with adjunct faculty based on the level of dedicated support evident from an analysis of their institutional websites. The current information offered in the overwhelming majority of the websites analyzed is unfocused, fragmented, and ill-suited to augment the adjunct's experience or performance at the institution. For most higher education institutions, explicit mention of adjunct faculty occurs only at the bare minimum, at the point of recruitment, and then little or nothing else is offered.

One of the conceptual issues with supporting adjunct faculty is how they fit into the classification system at the institution. A classical distinction at higher education institutions is between faculty, staff, and students. Often, adjunct faculty members exist in a hybrid or unclear classification where they are treated as faculty in some cases and an entirely different category in others. Email policies, for instance, may not provide adjunct faculty with the same privileges, or even email address, as faculty. Parking privileges at some institutions, likewise, may not be the same as regular faculty. However, these distinctions are frequently not made clear on the website or in policies and instead exist as informal or unspoken practices.

Website content is one way for the institution to facilitate and manage its relationship with their stakeholders. Pages devoted to particular groups or functions not only help the target group, it also helps the institution itself organize and assess how effective its activities are. For instance, an institution without an alumni page likely does not have a well-organized alumni program. Likewise, the lack of a well-organized adjunct faculty website indicates either that there are few connections or that those connections are not on the website. Thus, for instance, if there are no professional development events 
listed for adjunct faculty, does that mean that no events are organized or available for adjunct faculty? If there are grants available to faculty, does that include adjunct faculty as well? In general, a well-organized adjunct faculty resource system on the institution's website would indicate that adjunct faculty are wellintegrated into the institution. The data, however, suggest that the opposite is the case and that the website enhances the alienation that many adjunct faculty members experience throughout their careers.

At one university in the Pacific outside of this study, the Center for Teaching and Learning provides a model example for providing resources for adjunct faculty such as having an open invitation to all workshops and professional development activities. The center developed and maintained a dedicated page on the university website for adjunct faculty resources and information for new hires that is frequently updated (Chun \& Hargis, 2017).

\section{RECOMMENDATIONS}

The research indicated that very few institutions had dedicated public webpages for adjunct faculty, even while their job postings often indicated the importance of adjunct faculty for achieving the core mission of the institution. Given the issues faced by and the importance of adjunct faculty to the institution, this disconnection ought to be rectified. Protected web resources may be useful, but having a robust and dedicated public page on an institution's website for adjunct faculty, even if they are living remotely, is essential to provide information, news, and professional development resources that can be accessed as needed. The scope and quality of the resources should be compared to those found at other higher education websites even if few exemplary ones currently exist and they should be compared to ensure that the resources are responding to their needs.

The needs of the adjunct faculty ought to be extended beyond hiring and grade submission. Even if adjuncts are not full-time employees, many of them have been long-term members of the institution and in any event ought to be supported as active members of the academic community. The goal should be a page tailored for adjunct faculty during their entire engagement with the institution, starting with their initial hire, but not ending with their employment paperwork. Having a dedicated central resource location that is updated frequently on the institutional website can aid adjunct faculty in shortening the learning curve for new members to the institution by providing general resource information, employment information from human resources, allows for an ongoing resource of tools and information for professional development, provides a positive perception from the administration that they value adjunct faculty as a critical workforce for the institution and providing campus news to keep adjunct faculty engaged and involved.

The dedicated adjunct faculty webpage should also consider issues that arise when faculty live remotely, which means not only that they cannot come to campus to resolve problems, but also that they may not even know who to ask for help. From an access perspective, it may well be the case that all of the necessary information is already available on the institution's website. However, just as it is often not clear to adjunct faculty what content does and does not apply to them, with remote faculty it would be even more difficult to piece together a coherent understanding of what resources are available because they do not even experience the face-to-face informal help that can be found on campus. It is important for those who work on campus to understand how disorienting the campus can be for those who work remotely, and for those who are not part of the day-to-day institutional activities that provide a grounding at the college or university.

\section{LIMITATIONS OF THE STUDY}

The study was limited to sampling non-profit four-year universities. Therefore, for-profit institutions, community colleges, and large research universities were not part of the sample. The more focused sample helps to limit some variations and allows for subsequent research on the other classifications of institutions. In general, the content connected to adjunct faculty does not depend on access to significant resources to create or maintain those resources, which entails that the existence of a well thought-out 
adjunct faculty website depends more on the priorities of the institution and less on the access to resources.

This study also did not explore the possibility that adjunct faculty resources are located in a password-protected area or distributed through email. Resources behind a password wall could be analyzed in subsequent studies where access to those areas is secured by the institution. It should be noted, however, that protected adjunct faculty resources with passwords makes them more difficult to access, and for prospective or new adjunct faculty, potentially inaccessible. Likewise, even if there was a substantial adjunct support section on the site that required a password, it may still be the case that a public page would exist that directed the adjunct faculty to the login screen.

The study did not consider whether the institution offers an online course or an orientation for adjunct faculty. Orientation, whether online or face-to-face, can be an important aspect of connecting adjunct faculty to the institution and merits its own research. However, orientations often do not provide persistent resources for adjunct faculty. The focus in this study is the web-based, largely passive, resources that are available for adjunct faculty to access as the need or interest arises.

\section{RECOMMENDATIONS FOR FUTURE WORK}

This exploratory study focused on a content analysis of publicly available websites explicitly directed to adjunct faculty. A complementary study would focus on the resources made available on an institution's intranet. As many employment-related resources are often hidden from view, such a project would not only provide a more comprehensive sense of what resources are available to internal personnel, but would also allow a consideration for how frequently such information is kept from public view. Finally, with a broad sample, it would also become possible to determine the ratio of institutions that make the information available publicly, that make it available privately, and that simply do not make it available at all.

The current study also has not considered the attitudes or opinions of people at the institutions, including adjunct faculty, but also administrators and faculty in tenure-tracked positions. Do the adjunct faculty believe that they are being given enough support? What types of support would be useful? Such opinion surveys can offer insight into how well the institution is perceived to be supporting adjunct faculty, although such surveys are limited insofar as the adjunct faculty themselves may not realize or be able to articulate the types of support that could be offered.

The study focused on a particular random sample of institutions that belonged to specific classifications. Subsequent research could focus on different types of institutions, such as community colleges, for-profit universities, and research-focused institutions. Are community colleges more supportive of adjunct faculty than, say, large public universities? Research could also be expanded to consider international variations. Is the level of institutional support material for adjunct faculty found on websites in the United States similar or different from other countries such as South Korea or Canada? Hence, variations in the experience of adjunct faculty, and in the organization of the educational workforce in different countries, could also be highlighted.

The research also indicated that the content of the faculty handbook, especially if tailored to adjunct faculty, is an important source of information that merits further research. What is typically included in a handbook? What could be included? The interaction between the adjunct faculty handbook and the webpages devoted to the needs of adjunct faculty could also be pursued, where the handbook likely performs a regulatory role by including static policies and procedures whereas the webpage creates a more dynamic engagement that brings the adjunct faculty member into the academic life of the institution. Many different strategies could be designed and tested.

Finally, further research could be undertaken to explore why there are few examples of institutions making a conscious effort to use the public-facing website to support adjunct faculty. Is the lack of focused resources an intentional decision on the part of the administration or the web designers? Have the resources not been created because adjunct faculty are simply not part of the campus discussions concerning resource allocations? Is there an attempt to hide the work conditions faced by adjunct faculty 
members? Another possibility is a desire to not publicly admit that the institution relies heavily on adjunct faculty to achieve its primary mission. There are countless other potential reasons that merit further exploration as a way to improve the general conversation occurring in higher education over the support of adjunct faculty members.

\section{CONCLUSION}

As logistical practices in higher education come to rely more on adjunct faculty, the institutional support for adjunct faculty becomes increasingly essential. Having a dedicated webpage for adjunct faculty on an institution's website provides a broader narrative of the member's connection to the institution. Making that webpage public or partially public provides access to prospective and former faculty as well as current ones. Colleges and universities can thus create stronger connections and support opportunities for their adjunct faculty through such a dedicated page, which will in turn improve the institution. Given that being an adjunct faculty is becoming a longer-term career path for many in academia, the importance of having resources readily available has become critical. However, despite the increased need for these resources, the evidence indicates that many institutions have not created them. With few exceptions, adjunct faculty members have no resources tailored to their specific needs. It is a support challenge that higher education institutions need to acknowledge. 


\section{REFERENCES}

Almahamid, S. M., Tweiqat, A. F., \& Almanaseer, M. S. (2016). University website quality characteristics and success: Lecturers' perspective. International Journal of Business Information Systems, 22(1), 41-61.

Berschback, R. (2010). Everything that new and adjunct business faculty members should ask about teaching, but don't know enough to ask. Journal of College Teaching \& Learning, 7(5), 13-24.

Carnegie Foundation (2015). Carnegie Classifications Data File. Retrieved from carnegieclassifications.iu.edu/downloads/CCIHE2015-PublicDataFile-01Feb16.xlsx.

Chun, H., \& Hargis, J. (2017). The empowerment and inclusion of adjunct faculty: A Case Study. Proceedings from the Hawaii International Conference on Education (HICE), January 3-6, 2017.

Datray, J. L., Saxon, D. P., \& Martirosyan, N. M. (2014). Adjunct faculty in developmental education: Best practices, challenges, and recommendations. Community College Enterprise, 20(1), 34-47.

Dolan, V. (2011). The isolation of online adjunct faculty and its impact on their performance. International Review of Research in Open and Distance Learning, 12(2), 62-77.

Fruscione, J. (2014, July 25). When a college contracts 'adjunctivitis,' it's the students who lose. PBS Newshour. Retrieved from http://www.pbs.org/newshour/making-sense/when-a-collegecontracts-adjunctivitis-its-the-students-who-lose

Hoyt, J. E. (2012). Predicting the satisfaction and loyalty of adjunct faculty. Journal of Continuing Higher Education, 60(3), 132-142.

Komos, M. (2013). "Thanks for asking": Adjunct faculty members' views of effective teaching. Journal on Excellence in College Teaching, 24(4), 133-164.

Langen, J. M. (2011). Evaluation of adjunct faculty in higher education institutions. Assessment \& Evaluation in Higher Education, 36(2), 185-196.

Morton, D. R. (2012). Adjunct faculty embraced: The institution's responsibility. Christian Education Journal, 9(2), 396-407.

Rutz, C., Condon, W., Iverson, E. R., Manduca, C. A., \& Willett, G. (2012). Faculty professional development and student learning: What is the relationship? Change, 44(3), 40-47.

Schieffer, L. (2016). The benefits and barriers of virtual collaboration among online adjuncts. Journal of Instructional Research, 5, 109-125.

Shobe, M. A., Murphy-Erby, Y., \& Sparks, J. (2014). Mentorship efforts to support part-time social work faculty members. Mentoring \& Tutoring: Partnership in Learning, 22(5), 446-460. doi: $10.1080 / 13611267.2014 .983328$

Webb, A. S., Wong, T. J., \& Hubball, H. T. (2013). Professional development for adjunct teaching faculty in a research-intensive university: Engagement in scholarly approaches to teaching and learning. International Journal of Teaching and Learning in Higher Education, 25(2), 231-238.

Yakoboski, P. J. (2016). Adjunct views of adjunct positions. Change, 48(3), 54-59. doi:10.1080/00091383.2016.1170553 